\title{
DIAGNOSIS OF CONGENITAL ANOMALIES OF KIDNEY AND URETER BY ULTRASONOGRAPHY
}

\author{
HALIM FN ${ }^{1}$, SARKER MA², NAZLEE $F^{3}$, ISLAM MN ${ }^{4}$
}

\begin{abstract}
:
Present study was conducted to investigate the diagnostic accuracy of transabdominal ultrasonography in correlation with IVU in suspected patients of Congenital anomalies of kidney and Ureter. In study, ultrasonography and IVU was done in $\mathbf{5 0}$ clinically suspected patients of congenital anomalies of kidney that was admitted in BSMMU, BIRDEM \& DMCH during the period of July 2008 to May 2009. Patients of all ages and both sexes were included. Findings of USG and IVU were correlated. Sonographically abnormalities were diagnosed in $46(92 \%)$ cases, out of which $45(95.7 \%)$ also diagnosed by IVU and 1 (33.3) was normal in IVU. Out of 4 (8\%) Sonographically demonstrated normal cases, 2 $(4.3 \%)$ were proved normal by IVU and $2(66.7 \%)$ cases which missed by sonography were diagnosed by IVU. Sensitivity of ultrasonography in diagnosing congenital kidney disease was $95.7 \%$ and specificity was $66.7 \%$, positive predictive value was $\mathbf{9 7 . 8 \%}$, negative predictive value was $\mathbf{5 0 . 0 \%}$ and accuracy was $\mathbf{9 4 . 0 \%}$.
\end{abstract}

So, we conclude that ultrasonography has significant sensitivity, specificity, positive predictive value, and accuracy in diagnosis of congenital kidney anomalies correlating with IVU. As such, USG can be considered as an appropriate imaging tool for diagnosis of congenital anomalies of kidney.

\section{Introduction:}

The kidneys are located in a retroperitoneal position on either side of the vertebral column and against the psoas muscles. In a normal adult, each kidney is about 11 centimeters in length and 150 gm in weight. Renal length in childhood depends on the age, gender, race, weight, and height of the child. Accordingly, a renal length normogram based on the ultrasound measurement in pediatric patients may be used to

1. Dr. Fathima Nusrath Halim, MBBS, M phil in Radiology and Imaging. Assistant Professor, Dept. of Radiology and Imaging, Holy Family Red Crescent Medical College.

2. Dr. Mohammad Ali Sarker, MBBS, DMRD. Professor \& Head Dept. of Radiology and Imaging, Holy Family Red Crescent Medical College.

3. Dr. Farah Nazlee, MBBS.Medical officer, Dept. of Radiology and Imaging, Bangabandhu Sheikh Mujib Medical University, Dhaka

4. Dr. Md. Nazrul Islam, MBBS, MS (Paediatric Surgery). Medical officer, Dept. of Paediatric Surgery, Bangabandhu Sheikh Mujib Medical University, Dhaka

Correspondence: Dr. Fathima Nusrath Halim, Assistant Professor, Holy Family Red Crescent Medical College and Hospital 1, Eskaton Garden Road, Dhaka, e-mail: nusrath_shetu@yahoo.com assess kidney size. The right kidney usually is smaller than the left, and also lies one to two centimetres lower than the left kidney ${ }^{1}$.

Congenital anomalies of the kidney and urinary tract (CAKUT) include renal maldevelopment (aplastic, dysplastic or hypoplastic kidneys), urinary tract obstruction and vesicoureteral reflux. Children with CAKUT often have fewer nephrons at birth than normal ${ }^{2}$.

Approximately $45 \%$ of new dialysis cases among Japanese pediatric patients involve cystic, hereditary, and/or congenital disorders of the kidney and urinary tract. Two-thirds of these are caused by congenital anomalies of the kidney and urinary Tract (CAKUT) $)^{3,4}$. In a North American statistical report on chronic renal failure in children, nearly two-thirds of children and adolescents with chronic renal failure were diagnosed with congenital structural anomalies of the kidneys.

The incidence of major types of these anomalies at birth is: Obstructive uropathy-1/500-1000, Bilateral aplastic kidney- 1/2500-5000, Unilateral aplastickidney 1/1000, Dwarf kidney-1/500, Multicystic 
dysplastic kidney (MCDK) -1/4300, Vesicoureteral reflux- (VUR) 1/10-100, Horseshoe kidney- 1/400500 , Double renal pelvis- $1 / 20-125$, Posterior urethral valves (males)- $1 / 800-25000^{5}$.

In the last century, various diagnostic tools, which are based on different phenomena in physics, have been incorporated into medicine. They include sound waves, laser waves, magnetic devices, optical instruments, etc. Among them, ultrasound has been used in clinical applications for the last forty years ${ }^{6}$.

The various imaging modalities utilized in the field of Pediatric Urology include: i) Plain radiography, ii) Contrast studies (with fluoroscopy), iii) Ultrasound (US) iv) Computerized tomography (CT scans), v) Nuclear medicine imaging, vi) Magnetic resonance imaging (MRI), vii) Rotational fluoroscopic tomography (RFT), vii) Positron emitted tomography (PET scan).

Intravenous urography (IVU) (IVP) or excretory urography is one of the oldest uroradiologic imaging modalities. Until the advent of MR urography and CT urography, this was the only means by which to evaluate both the morphology and the function of the upper urinary tract. However, due to concerns of radiation exposure in children and the advent of the newer modalities, the indications for IVU have evolved and it should be tailored to answer the individual patient's clinical query ${ }^{7}$.

The diagnostic capability of ultrasound images is based on the well-known observation that, when sound waves are sent to different organs and structures, those that reflect sound waves back to the transducer (such as the liver) seem white or echogenic. Conversely, the structures that do not reflect back sound waves (such as fluids) appear black or anechoic. In addition, soft tissues appear as grey images ${ }^{6}$.

Although more advanced diagnostic tools have been recently incorporated along with the ultrasound images, conventional sonography is still one of the most common imaging methods used in the diagnosis and follow-up of patients with kidney diseases. Ultrasound is a non-invasive, reliable, widely available, and affordable diagnostic tool. In some cases, ultrasound plays a major role in early detection and also in applying proper management ${ }^{8}$.

Current study was carried-out to find out the role of ultrasonography in the evaluation of congenital anomalies of kidney and ureter and to correlate it with intravenous urogram (IVU). So far we know, no previous study was carried-out to explore this modalities for diagnosing CAKUT in Bangladesh.

\section{Materials and Method:}

This cross sectional study was carried out in the Department of Radiology and Imaging and Department of Pediatric Nephrology of BSMMU, BIRDEM and Dhaka Medical College Hospital, Dhaka from June 2008 to May 2009. All 50 patients who having clinical evidence of congenital anomalies of kidney or an incidental finding are included in this study. After evaluation of all patients by detail history and clinical examination underwent ultrasonographic examination (USG) were performed with SIEMENS Sonoline prima scanner $3.5 \mathrm{MHz}$ transducer and then contrast radiography (IVU) was done. All this information was collected in a pre designed a structured data collection sheet which involves questionnaire, clinical findings, USG findings, IVU findings. The aims and objectives of the study along with its procedure, alternative diagnostic methods, risks and benefits of this study was explained to the patients in easily understandable local language and then informed consent was taken from each patient. A statistical analysis of the results was obtained by using window based computer software devised with Statistical Packages for Social Sciences (SPSS-13) (SPSS Inc, Chicago, IL, USA).

\section{Result:}

In USG diagnosis, PUJ obstruction 15 (32.6\%), unilateral agenesis $8(17.4 \%)$, horse shoe $6(13.0 \%)$, polycystic KD 4 (8.7\%), duplex 3 (6.5) and ectopic $10(21.7 \%)$ and in IVU diagnosis PUJ obstruction 15 $(31.9 \%)$, unilateral agenesis $8(17.0 \%)$, horse shoe 6 (12.8\%), polycystic KD 3 (6.4\%), duplex 5 (10.6) and ectopic 10 (21.3\%). (Table-I)

Table-I

Distribution of the respondents' USG and IVU diagnosis

\begin{tabular}{lcc}
\hline Diagnosis & USG diagnosis & IVU diagnosis \\
\hline PUJ obstruction & $15(32.6)$ & $15(31.9)$ \\
Unilateral agenesis & $8(17.4)$ & $8(17.0)$ \\
Horse shoe & $6(13.0)$ & $6(12.8)$ \\
Polycystic KD & $4(8.7)$ & $3(6.4)$ \\
Duplex & $3(6.5)$ & $5(10.6)$ \\
Ectopic & $10(21.7)$ & $10(21.3)$ \\
\hline Total & $46(100.0)$ & $47(100.0)$ \\
\hline
\end{tabular}

Sonographically abnormalities were diagnosed in 46 $(92 \%)$ cases, out of which $45(95.7 \%)$ also diagnosed 
by IVU and 1 (33.3) was normal in IVU. Out of 4 (8\%) Sonographically demonstrated normal cases, 2 (4.3\%) were proved normal by IVU and $2(66.7 \%)$ cases which missed by sonography were diagnosed by IVU. Kappa value indicates moderate agreement between these two tests which is statistically significant. (Table-II).

Table-II

Distribution of the respondents' USG diagnosis by IVU diagnosis

\begin{tabular}{lccc}
\hline USG diagnosis & \multicolumn{2}{c}{ IVU diagnosis } & Total \\
& Disease & No disease & \\
\hline Disease & $45(95.7)$ & $1(33.3)$ & $46(92.0)$ \\
No disease & $2(4.3)$ & $2(66.7)$ & $4(8.0)$ \\
Total & $47(100.0)$ & $3(100.0)$ & $50(100.0)$ \\
\hline
\end{tabular}

Kappa $=0.54, p=0.001$

Sensitivity of ultrasonography in diagnosing congenital kidney disease was $95.7 \%$ and specificity was $66.7 \%$, positive predictive value was $97.8 \%$, negative predictive value was $50.0 \%$ and accuracy was $94.0 \%$. (Table-III)

Table-III

Validity test

\begin{tabular}{lcc}
\hline Test & Value & $95 \% \mathrm{Cl}$ \\
\hline Sensitivity & 95.7 & $92.9-97.4$ \\
Specificity & 66.7 & $22.8-93.2$ \\
PPV & 97.8 & $95.0-99.6$ \\
NPV & 50.0 & $17.1-69.9$ \\
Accuracy & 94.0 & $88.7-97.2$ \\
\hline
\end{tabular}

\section{Discussion:}

The current study was a cross sectional study to explore the role of ultrasonography (US) in evaluation of congenital anomalies of kidney and ureter. Fifty patients of clinical diagnosed cases of congenital anomalies of kidney were enrolled and ultrasonography and IVU was performed in all cases.

In our study, out of 50 cases, sonography detects 46 positive cases of CAKUT. From these positive cases 45 cases was confirmed by IVU. Out of 45 cases, most prevalent anomaly was PUJ obstruction $(33.33 \%)$. Tsuchiya et. al. in their study evaluated the value of early abdominal ultrasonography for diagnosis of CAKUT. They yield 32 positive cases $(0.60 \%)$ cases of CAKUT after $2^{\text {nd }}$ screening of 1-4 months babies. In their study, most frequent encountered was obstructive uropathy (15 cases). Small kidney and vesicoureteric reflux were next in frequency. They concluded that ultrasonography was effective for early detection of renal and urinary tract anomalies ${ }^{9}$.

Renal agenesis can easily detect by ultrasounography based on the complete absence of renal tissue on the corresponding side ${ }^{10}$. In our study, we found 8 $(17.78 \%)$ cases of unilateral renal agenesis which was also detected by IVU. However, Hiraoka et al. \& Wacksman et al. suggests that non-visualization of renal tissues with ultrasound in later childhood rather than early infancy is more likely to be regressed renal dysplasia than renal agenesis ${ }^{3,11}$.

Ashgar et al found their study, 21 cases of renal ectopia and 4 cases of horse shoe shaped kidney. They were inconclusive about the diagnosis of one case of renal ectopia and one cases of horse shoe shaped kidney by ultrasonography and which were confirmed by contrast radiography. As such, they concluded that ultrasonography is a sensitive investigation for the diagnosis of renal ectopia and horse shoe shaped kidney ${ }^{12}$. However, such problem was not arises in our study. We found 10 cases of renal ectopia and 6 cases of horse shoe shaped kidney by ultrasonography which was 100 agreement with IVU.

Romero et al, in their study, asses the diagnostic accuracy of antenatal sonography in population at risk. There was no false positive result in their study. They concluded that ultrasound is a valuable tool in antenatal diagnosis of infantile polycystic kidney disease ${ }^{13}$. In our study we detect at first 4 cases of polycystic kidney disease by USG in which 3 cases were agreement with IVU. However, one case was normal by IVU

Out of $4(8 \%)$ Sonographically demonstratd normal cases, $2(4.3 \%)$ were proved normal by IVU and 2 $(66.7 \%)$ cases which missed by sonography were diagnosed as duplex by IVU. As such, total confirmed cases of duplex were 5. Duplex kidney have been diagnosed solely on the basis of hydronephrosis in one or more poles of kidney. Certain ultrasonic features have been described as being more accurately associated with a duplex kidney. This findings includes presence of 2 separate non communicating renal pelvis, dilated ureters, cystic structure within one pole and ecogenic cyst in the blader. If these finding are not present it can be misdiagnosed by ultrasonography ${ }^{14}$. 


\section{Conclusion:}

Sensitivity of ultrasonography in diagnosing congenital kidney disease was $95.7 \%$ and specificity was $66.7 \%$, positive predictive value was $97.8 \%$, negative predictive value was $50.0 \%$ and accuracy was $94.0 \%$. So, ultrasonography has significant sensitivity, specificity, positive predictive value, and accuracy in diagnosis of congenital kidney anomalies correlating with IVU. However, a large controlled study should be carried out to observe accuracy of ultrasonogram in evaluation of congenital anomalies of kidney and ureter.

\section{References:}

1. Chen JJ, Pugach J, Patel M, Luisiri A, Steinhardt GF. The renal length nomogram: Multivariable approach. J Urol 2002; 168 (5): 2149-52.

2. Hiraoka M. Medical management of congenital anomalies of the kidney and urinary tract. Pediatrics International 2003; 45:624-633.

3. Hiraoka M, Tsukahara H, Ohshima Y, Kasuga K, Ishihara Y, Mayumi M. Renal aplasia is the predominant cause of congenital solitary kidneys. Kidney Int 2002; 61:1840-4.

4. Fivush BA, Jabs K, Neu AM. Chronic renal insufficiencyin children and adolescents; the 1996 annual report of NAPRTCS. Pediatr. Nephrol 1998; 12: 328-37.

5. Teele RL, Share JC. Renal screening, infection of the urinary tract, abdominal masses. In: Teele $\mathrm{RL}$, Share JC eds. Ultrasonography of Infants and Children. Philadelphia: WB Saunders 1991: pp. 137-316.
6. Yen K, Gorelick MH. Ultrasonund application for pediatric emergency: a review of current literature. Peditr Emerg Care 2002; 18 (3): 226-34.

7. Choyke PI. The urogram: Are rumors of its death premature? Radiology 1992; 184: 33-4.

8. Gheissari A. The Place of Ultrasound in Renal Medicine. Saudi journal of kidney and transplantation 2006; 17 (4): 540-548.

9. Tsuchiya M, Hayashida M, Yanagihara T, Yoshida Junko, Takeda S. Ultrasound screening for renal and urinary tract anomalies in healthy infants. Pediatrics International 2003; 45: 617-623.

10. Masahiro $\mathrm{H}$. Medical management of congenital anomalies of the kidney and ureter. Pediatrics international 2003; 45: 624-633.

11. Wacksman J, Phipps L. Report of the multicystic kidney registry: preliminary findings. J. Urol 1993; 150: 1870-2.

12. Asghar M, Wazir F. Prevalence of renal ectopia by diagnostic imaging. Gomal Journal of Medical Sciences 2008; 6 (2): 72-76.

13. Romero $R$, Cullen $M$, Jeanty $P$, Grannum $P$, Reece $E A$. The diagnosis of congenital renal anomalies with ultrasound. II. Infantile polycystic kidney disease. Am J Obs and Gynecol 1984:150 (3): 259-62.

14. Thurston W, Wilson SR, The Urinary Tract. In: Rumack CM, Wilson SR, Charboneau JW eds. Diagnostic Ultrasound, 3rd edition. China: Elsevier Mosby; 2005: pp. 321-93. 